\title{
Estimation of the Prophylactic Effect of the Egyptian Propolis Extract against Aluminum Silicate Toxicity on Some Organs of Albino Rats: Growth Performance and Histochemical Studies Ali H. Abu-Almaaty ${ }^{1}$, Yasmin M. Abd El-Aziz ${ }^{1 *}$, Nahed A. Omar ${ }^{2}$ , Ahmed M. Abdeen ${ }^{3}$
}

1- Zoology Department, Faculty of Science, Port Said University, Port Said,2-Zoology Department, Faculty of Science, Damietta University, Egypt.3-Zoology Department, Faculty of Science, Mansoura University, Egypt

* Corresponding author: Yasmin Mohamed Abd El-Aziz, Tel: +20 1005718455, E-mail: yasminabdelaziz2012@yahoo.com

\section{ABSTRACT}

Background: the liver is a critical organ because it contains most of the accumulated metals where toxic effects can expected. Also, the lung is directly affected by receiving aluminum as aluminum silicate. Exposure of aluminum leads to production of free radicals that damage living organs and tissues. Aim of the work: this study aimed to evaluate the nucleic acid content in liver, lung and cerebellum tissues intoxicated by aluminum silicate (AIS) and the possible ameliorative effect of propolis extract (PP).

Material and methods: Forty male albino rats (weighting 100-120 grams) were categorized randomly into four groups, ten rats on each group $(\mathrm{n}=10)$. The $1^{\text {st }}$ group considered as the healthy control group. The $2^{\text {nd }}$ group received $200 \mathrm{ml} \mathrm{PP} / \mathrm{kg}$ b.wt., day after day by stomach gavage. The $3^{\text {rd }}$ group was injected intraperitoneally by $20 \mathrm{mg} \mathrm{AlS} / \mathrm{kg}$ b.wt., twice weekly. The $4^{\text {th }}$ group was treated with AlS in addition to PP as the same doses as in the $2^{\text {nd }}$ and $3^{\text {rd }}$ groups. After two months for each group. Liver, lung and cerebellum organs were harvested. Results: decreased body weight gain of rats was realized with weakly stained nucleic acids contents in liver, lung and cerebellum tissues that intoxicated by AlS. While, using the supplemented treatment (PP) at the same time with the induction of AlS compound showed an ameliorative effect on the nucleic acid contents.

Conclusion: propolis has anti-oxidant by inhibiting AlS toxicity on nucleic acids in the different experimental organs of rats.

Keywords: aluminum silicate, propolis extract, nucleic acids, liver, lung, cerebellum.

\section{INRODUCTION}

In the last decades, aluminum (Al) is imagined as the third most massive element in the environment in which it is mixing with silicon, oxygen, nitrogen and other elements. It is found in the common nature and in the earth from the ground to water. In the other hand, silica is considered as the second most using element which plays a focal role in running the solubility of alumino-silicate minerals that comprise two thirds of the minerals in the earth coat ${ }^{(\mathbf{1})}$. Whereas, aluminum silicate (AlS) is found in many industrial applications like porcelain dishes, ceramic pots, clays, glasses, stones, pharmaceutical products such as aspirin, vaccines, antacids, antiperspirants and allergen admission from which the element enters the animal body ${ }^{(\mathbf{1}-\mathbf{3})}$. Aluminum distributes in varying human tissues including liver, lung, brain, heart, blood, kidney, bone and other organs (4-6) and the silica caused fibrogenic, carcinogenic and mutagenic cases (7). Propolis is bee glue and known as a resinous material that is collected from vary plants excretions at any climate. The bee workers are used this resin for protection of their beehives versus predators or for sticking any opens and scratches which occurring from the different seasons. At folk medicine, the Greek physicians used the raw propolis for improving of the gastrointestinal functions, anti-aging, inhibit tumor, anti-fatigue as well as others benefits. The propolis has powerful anti-inflammatory and antioxidant properties which that defense the damaging affects against aluminum toxicity ${ }^{(8-10)}$. This study aimed to evaluate the toxicity of aluminum silicate (AIS) admitted to rat models among their organs (liver, lung and cerebellum tissues). The toxicity evaluation was measured by their growth performance and histochemical investigations (demonstration of nucleic acids). In addition to the ameliorative effect of propolis extract (PP) in rats suffered from AlS toxicity.

\section{MATERIALS and METHODS Extraction of propolis}

The Egyptian raw propolis was taken from beehive in the Faculty of Environmental Agricultural Science, Sinai University, North Sinai, Egypt. The propolis extract was prepared by the procedure of Cunha et al. ${ }^{(11)}$.

\section{Experimental animal}

Forty male albino rats (Rattus norvegicus) weighting 100-120 grams. The rats were purchased from the Faculty of Veterinary Medicine, Suez Canal University, Ismailia, Egypt. Rats were housed in plastic cages and received water and diet ad libitum at good conditions for eight weeks (experimental period). Animals were categorized randomly into four groups, ten rats in each group ( $\mathrm{n}=10$ rats). The first group was considered as the control one. The second group was received $200 \mathrm{ml}$ of propolis extract per $\mathrm{kg}$ b.wt., day after day by stomach gavage tube. The third group was injected intraperitoneally (IP) by $20 \mathrm{mg}$ of aluminum silicate per kg b.wt., twice a week. The forth group was treated with aluminum silicate plus propolis extract as 
similar to doses in second and third groups. After twenty-four hours from the end of experimental period (eight weeks), the rats were dissected and liver, lung and cerebellum organs were harvested for the experimental examinations.

\section{Ethical approval:}

This study was conducted in accordance with ethical procedures and policies approved by Animal Care and Use Committee of Faculty of Medicine, Port Said University, Egypt.

\section{Growth performance}

During the experimentation time, the body weight was measured of each rat, three times per week. Then, we calculated the body weight gain by using this equation: body weight gain $(\mathrm{BWG})=$ the till weight the previous weight.

Histochemical evaluations for the nucleic acid contents

The freshly collected liver, lung and cerebellum organs were fixed in the buffered formalin solution for 48 hours; then, the organs were transferred to dehydrating ascending series of ethyl alcohol and cleared in pure xylene solution. The specimens were embedded in parablast wax and $5 \mu \mathrm{m}$ sections were made. For demonstration of nucleic acids (deoxyribonucleic acid (DNA) and Ribonucleic acid (RNA)) in liver, lung and cerebellum specimens were stained by specific stains as Feulgen nuclear reaction (FNR) for DNA (12) and methyl green pyronin-Y (MGP) for RNA ${ }^{(12,13)}$. Finally, the slides were mounted by DPX ${ }^{(\mathbf{1 4})}$. The stained experimental liver, lung and cerebellum sections were examined under light field microscope (Leica, Germany) ${ }^{(15)}$.

\section{RESULTS}

Measuring the body weight gain of rats after aluminum silicate induction and treatment by propolis extract

The calculated weekly body weight gain for all experimental groups and the healthy ones was detected in table 1, which showed marked depletion in rats which were treated with aluminum silicate (AIS) as compared to the healthy control one. This effect was noticed at $2^{\text {nd }}$ and $7^{\text {th }}$ weeks of AlS and extended to the end of the experimental period. In the other hand, administrated of propolis extract plus aluminum silicate (AlS+PP) that led to enhanced body weight gain when compared to AlS toxicity group (Table 1 and fig. 1).

Table 1: means of weekly body weight gain (g) for the different animal experimental groups

\begin{tabular}{|c|c|c|c|c|c|c|c|c|}
\hline Duration (week) & $1^{\text {st }}$ & $2^{\text {nd }}$ & $3^{\text {rd }}$ & $4^{\text {th }}$ & $5^{\text {th }}$ & $6^{\text {th }}$ & $7^{\text {th }}$ & $8^{\text {th }}$ \\
\hline Control (Cont.) & 27.8 & 29.7 & 30.2 & 30.6 & 31.5 & 33.2 & 33.5 & 39.2 \\
\hline Propolis extract (PP) & 29.9 & 30.1 & 31.2 & 31.5 & 32.0 & 35.2 & 36.8 & 41.2 \\
\hline Aluminum silicate (AlS) & 11.8 & 7.9 & 8.4 & 9.0 & 10.1 & 11.0 & 8.5 & 8.4 \\
\hline AlS+PP & 12.2 & 12.9 & 16.8 & 17.1 & 17.4 & 23.5 & 24.4 & 30.1 \\
\hline
\end{tabular}

Mean values of body weight gain for rats of all experimental groups

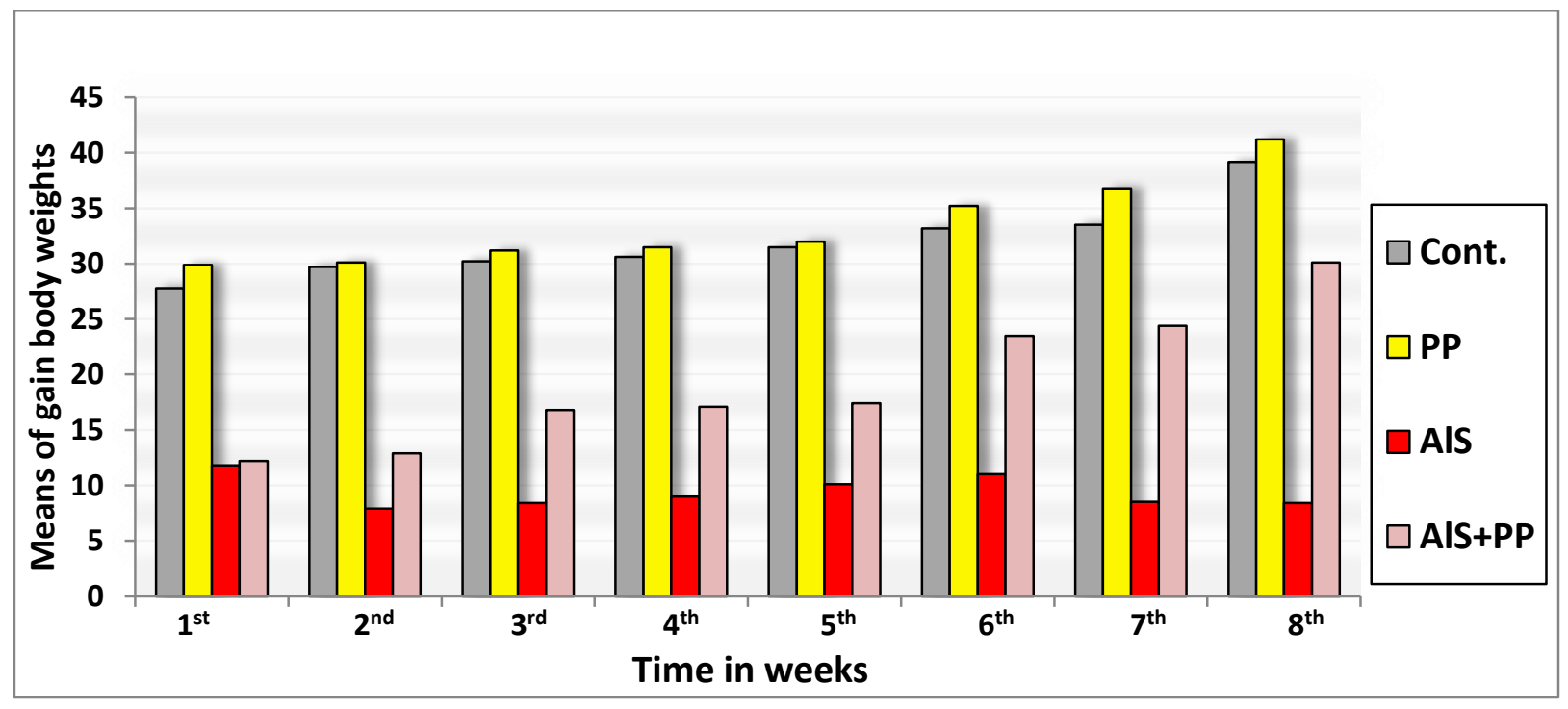

Fig. 1: means of variations of body weight gain in rat model of the different experimental groups 
Values of DNA contents in rat's liver, lung and cerebellum tissues which intoxicated by aluminum silicate and treated with propolis extract

To investigate the contents of DNA in the liver, lung and cerebellum tissues, specific stain (Feulgen nuclear reaction) was performed. In case of normal and propolis extract treated rats we detected homogeneously distribution purple color of FNR positive reaction in the nuclei of cells of liver, lung and cerebellum tissues (Fig. $\mathbf{2 a}, \mathbf{b}, \mathbf{e}, \mathbf{f}, \mathbf{I}, \mathbf{j}, \mathbf{m}, \mathbf{n})$. While, in the tissues of the experimental rats which were treated by aluminum silicate toxicity, the DNA contents were markedly diminished compared to the normal healthy rats (Fig. 2c,g,k,k). Surprisingly, co-supplement of propolis extract enhanced DNA contents as detected by FNR reaction in the tissues of liver, lung and cerebellum (Fig. 2d,h,l,p).
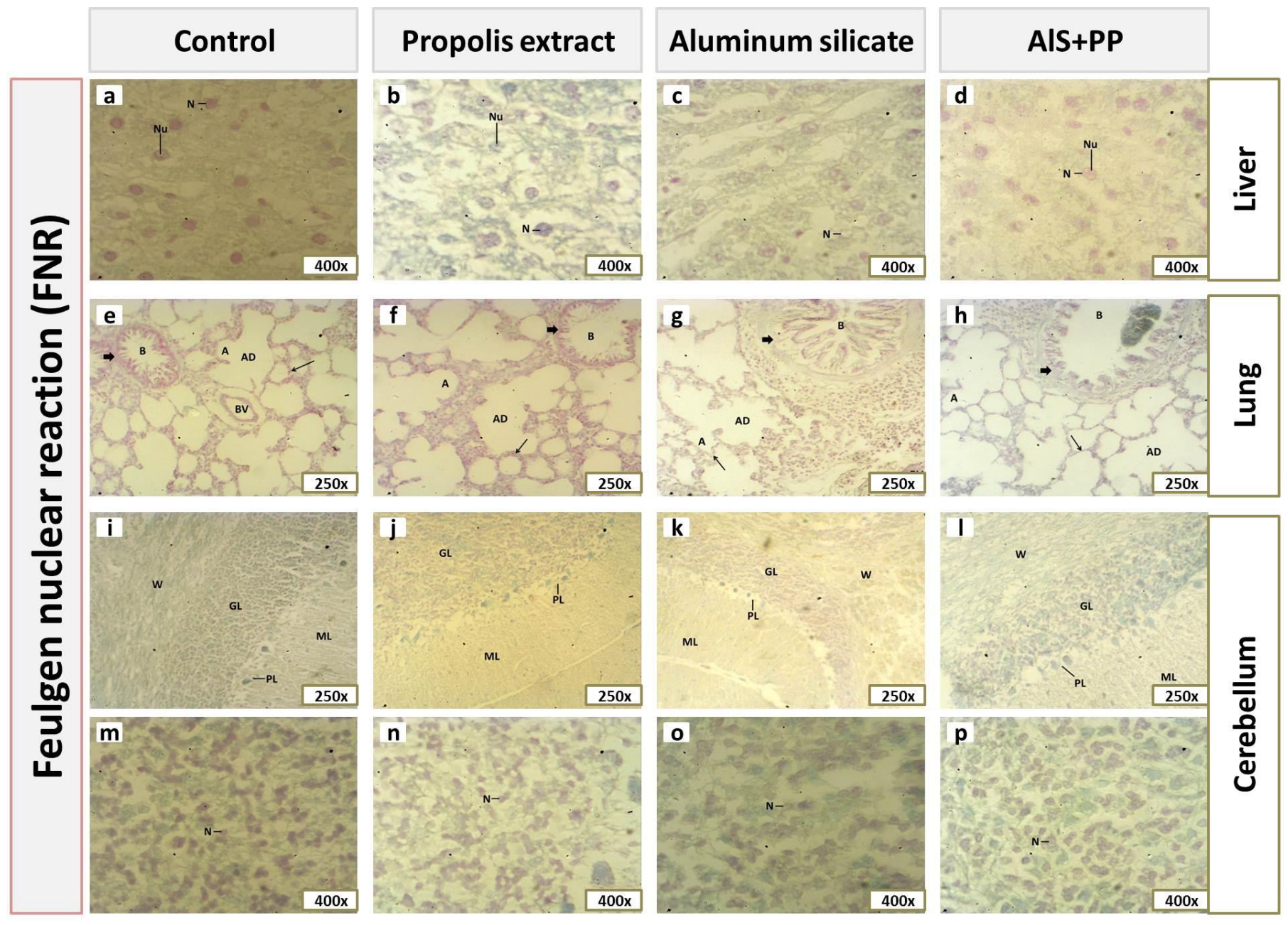

Fig. 2: a-p)

Tissues of the experimental rats stained with Feulgen nuclear reaction. Liver sections notice the nuclei (N) and nucleoli $(\mathrm{Nu})$. Cross sections of lung show the content of DNA in epithelium (thick arrow), alveolar ducts (AD), alveoli (A), bronchioles (B), thin alveolar septa (arrow) and blood vessels (BV). Cerebellum transverse sections recognize granular layer (GL), Purkinje cell layer (PL), molecular layer (ML), white matter (W) and reaction for DNA in nuclei $(\mathrm{N})$ of the granular layer.: a,m) Tissues from normal healthy rats show a purple color of FNR reaction for DNA contents in the hepatic, lung and cerebellum cells nuclei. b,n) Propolis extract (PP) treated rats seem as same as the control rats. c,o) Marked decrease of DNA contents is observed in almost tissues of rats that treated with aluminum silicate (AlS). d,p) Rats treated with aluminum silicate plus propolis extract (AlS+PP) demonstrate amelioration in the purple color of cellular nuclei of the tissues of the experimental rats. 
Down-regulation of RNA contents in rat liver, lung and cerebellum tissues which intoxicated by aluminum silicate and propolis extract coadministration

To evaluate the RNA contents in the experimental tissues used specific stain (methyl green pyronin-Y). In case of normal and propolis extract treated-rats homogeneously red color was detected in the cytoplasm of liver, lung and cerebellum tissues (Fig. 3a,b,e,f,I, $, \mathbf{j}, \mathbf{m}, \mathbf{n})$. While, in rats treated with aluminum silicate, the RNA contents were significantly reduced in liver, lung and cerebellum tissues compared to the control group (Fig. 3c,g,k,o). While, rats exposed to aluminum silicate plus propolis extract, showed enhanced RNA contents at examination with MGP reaction (Fig. 3d,h,l,p). In summary, propolis extract coadministration had ameliorative properties on the DNA and RNA contents in organs of the experimental rats exposed to aluminum silicate toxicity.

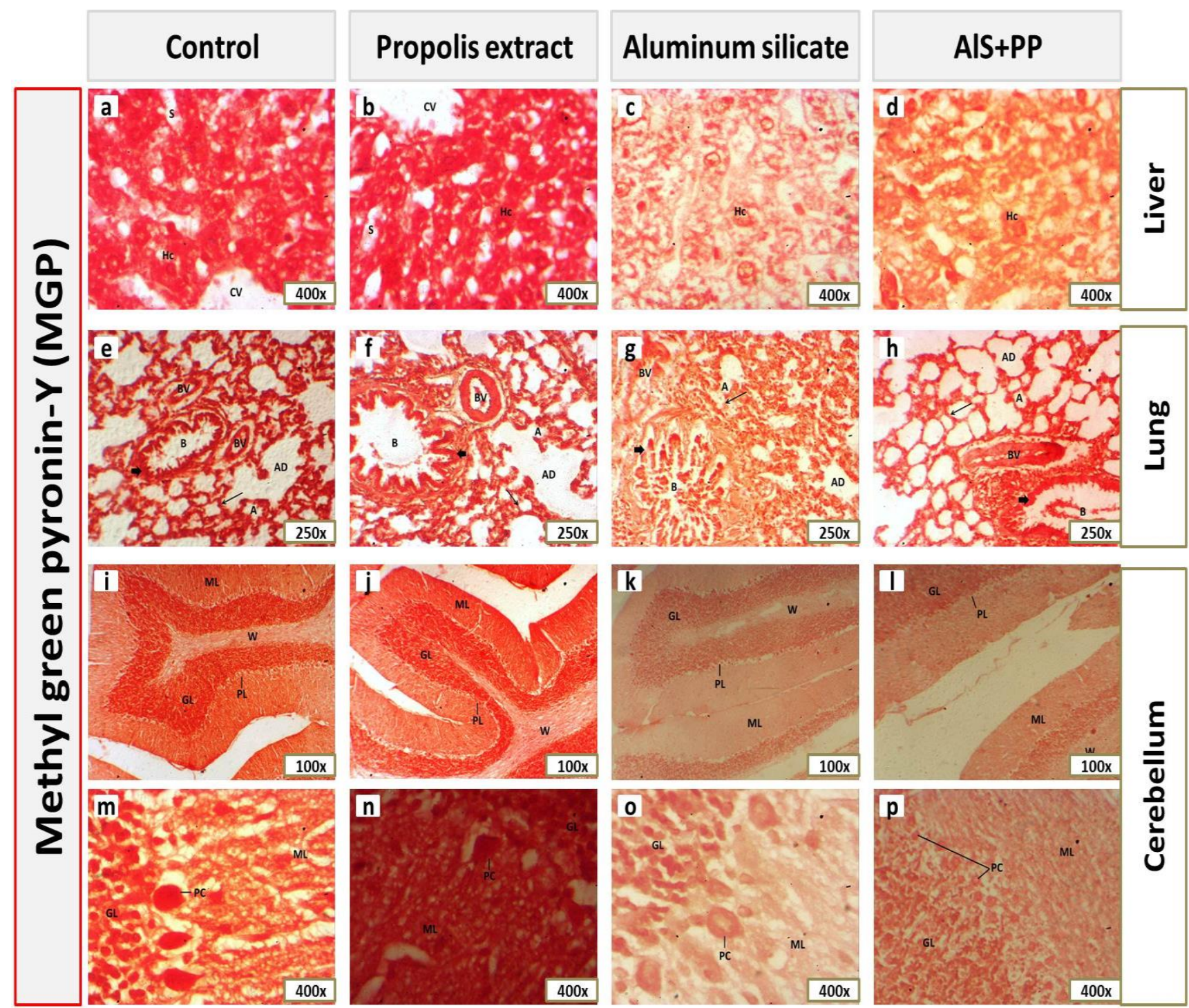

Fig. 3: a-p)

The experimental tissues are stained with methyl green pyronin. Liver sections detect the hepatic cells (Hc) around the central vein (CV) and hepatic blood sinusoid (S). Cross sections of lung show distribution of RNA content in the epithelium cells (thick arrow), alveolar ducts (AD), alveoli (A), bronchioles (B), thin alveolar septa (arrow) and blood vessels (BV). Cerebellum transverse sections show stained RNA in the cytoplasm of the three layers. Granular layer (GL), Purkinje cell layer (PL), Purkinje cells (PC), molecular layer (ML) and white matter (W). a,m) Control healthy tissues from liver, lung and cerebellum show red color of MGP for RNA contents in their cytoplasm. b,n) Sections of animals received propolis extract (PP) is similar to the healthy normal one. c,o) Rats treated with aluminum silicate (AIS) show a diminish of this reaction in all layers of tissues. d,p) Show some improvement in the red color of RNA inclusions in liver, lung and cerebellum tissues by this reaction after treatment with aluminum silicate in addition to propolis extract (AlS+PP). 


\section{DISCUSSION}

Survive of mammals is evaluated by the growth performance parameter. During our study, the body weight gain of male Albino rats group was decreased after treatment with aluminum silicate (AlS) compared to that of the control group. These results are in agreement with the studies of Koizumi et al., Zhu et al. and Allagui et al. ${ }^{(16-18)}$. They demonstrated a decrease of the body weight of animals treated with the clay or other several aluminum compounds, this reduction in the body weight was considered to disorder absorption, consumption of nutrients and organ injury that led to diminished body protein synthesis. In other hands, the used propolis extract in our study enhanced the body weight gain for rats after using aluminum silicate.

By histochemical analysis, there was serious depletion in contents of nucleic acids in the liver, lung and cerebellum tissues that induced by aluminum silicate by using the histochemical specific stains. Weak purple Feulgen stain of DNA contents was stored in tissues exposed to AlS toxicity and also, weak red pyronin-Y dye of RNA contents were detected in tissues exposed to AlS toxicity. In addition, the depletion of DNA contents is always associated with decline in the contents of RNA and then leads to inhibit the protein synthesis ${ }^{(19)}$. Aluminum salts binds to DNA and RNA then causes complex with enzymes and inhibits the activities of enzymes as alkaline and acid phosphatases, hexokinase, phosphooxydase, phosphodiesterase and protein synthesis ${ }^{(20)}$.

Aluminum had a genotoxic effect and a remarkable damage occur due link with DNA ${ }^{(21)}$. Some studies confirmed association of aluminum element with DNA, RNA, cellular membrane proteins and cellular membrane lipids, causing cellular injury ${ }^{(22,23)}$. Another study explained the severe damage in hepatic DNA due to aluminum administration ${ }^{(24)}$. This disorder occurred in both brain and cerebellum of the experimental rats ${ }^{(25)}$. DNA and RNA amounts for liver, kidney and spleen rat were depleted in their values because after exposure to acute and chronic intoxication of aluminum trichloride (26). DNA content in hepatocytes of rats which induced by $\mathrm{AlCl}_{3}$ demonstrated that most of their nuclei showed a weak Feulgen reaction of their chromatin granules ${ }^{(27)}$.

\section{CONCLUSION}

There was a definitive cytotoxic effect of aluminum silicate in the vital organs of the experimented rat models (liver, lung and cerebellum tissues). It could be improved by the propolis extract due to its antioxidant properties. Thus, inclusion of propolis in a normal balanced diet and take as a nutritional supplement may have a tremendous potential prophylactically to workers subjected to aluminum silicate pollution. The suggestion for further studies are needed for estimating the dosing of propolis extract and bee products as a nature supplements for their curative and prophylactic power in human health.

\section{REFERENCES}

1. Moller N, Christov $C$ and Weare J (2006): Thermodynamic models of aluminum silicate mineral solubility for application to enhanced geothermal systems. Proc. $31^{\text {st }}$ Workshop on Geothermal Reservoir Engineering, Sanford University, California, USA.

2. Verstraeten SV, Aimo L and Oteiza PI (2008): Aluminium and lead: molecular mechanisms of brain toxicity. Archiv. Toxicol., 82(11): 789-802.

3. Kawahara $M$ and Kato-Negishi $M$ (2011): Link between aluminum and the pathogenesis of Alzheimer's disease: the integration of the aluminum and amyloid cascade hypotheses. Int. J. Alzheimers Dis., 2011: $276393-276400$.

4. Al-Kahtani MA (2010): Renal damage mediated by oxidative stress in mice treated with aluminium chloride: protective effects of taurine. J. Biol. Sci., 10(7): 584595.

5. Abd El-Aziz YM, Abu-Almaaty AH, Omar NA, Abdeen AM and Zakaria MM (2019): Evaluation of protective effects of propolis against aluminium silicate toxicity in rats. Genetika, 51(1): 299-312.

6. Omar NA, Abu-Almaaty AH, Abd El-Aziz YM, Abdeen AM, Mohamed FEZA, Hashem MMM and Hammad S (2019): Impacts of Egyptian propolis extract on rat cerebellum intoxicated by aluminum silicate: histopathological studies. Environ. Sci. Pollut. Res. Int., 26(21): 22061-22068.

7. Nattrass C, Horwell CJ, Damby DE, Brown D and Stone V (2017): The effect of aluminium and sodium impurities on the in vitro toxicity and pro-inflammatory potential of cristobalite. Environ. Res., 159: 164-175.

8. Mahmoud ME and Elsoadaa SS (2013): Protective effect of ascorbic acid, biopropolis and royal jelly against aluminum toxicity in rats. J. Natural Sci. Res., 3(1): 102112.

9. Yousef MI and Salama AF (2009): Propolis protection from reproductive toxicity caused by aluminium chloride in male rats. Food Chem. Toxicol., 47(6): 1168-1175.

10. Oršolić $\mathbf{N}$ (2010): A review of propolis antitumor action in vivo and in vitro. J. Product. Med. Sci., 2(1): 1-20.

11. Cunha IBS, Sawaya ACHF and Caetano FM (2004): Factors that influence the yield and composition of Brazilian propolis extracts. J. Brazilian Chem. Soc., 15(6): 964-970.

12. Pearse A (1985): Histochemistry: Theoretical and Applied. $4^{\text {th }}$ ed., Vol. 2. Churchill Ltd, London. UK.

13. Kurnick NB (1955): Histological staining with methyl green pyronin. Stain Technol., 27: 233-242.

14. Fischer AH, Jacobson KA, Rose $J$ and Zeller $R$ (2008): Hematoxylin and eosin staining of tissue and cell sections. doi: 10.1101/pdb.prot4986.

15. Bancroft JD and Gamble $M$ (2008): Theory and Practice of Histological Techniques. Churchill Livingstone. Elsevier, London.

16. Koizumi MH, fujii S, Ono A, Hirose A, Imai T, Ogawa K, Ema M and Nishikawa A (2010): Two generation reproductive toxicity study of aluminum sulfate in rats. Reprod. Toxicol., 31: 219-230.

17. Zhu Y, Li X, Chen C, Wang F, Li J, Hu C, Li Y and Miao L (2012): Effects of aluminum trichloride on the trace. Elements and cytokines in the spleen of rats. Food Chem. Toxicol., 50: 2911-2915.

18. Allagui MS, Feriani A, Saoudi M, Badraoui R, Bouoni Z, Nciri R, Murat JC and Elfeki A (2014): 
Effects of melatonin on aluminium-induced neurobehavioral and neurochemical changes in aging rats. Food Chem. Toxicol., 70: 84-93.

19. Chambers RC, Laurent GJ and Westergen T (1998): Cadmium inhibits proteoglycan and procollagen production by cultured human lung fibroblasts. Am. J. Respir. Cell. Mol. Biol., 19(3): 498-506.

20. Ochmański W and Barabasz W (2000): Aluminum occurrence and toxicity for organisms. Przegl. Lek., 57(11): 665-668.

21. Exley C (2001): Aluminum and Alzheimer's Disease. Elsevier Sci., Amsterdam, New York. pp: 147-168.

22. Kumar V and Gill KD (2009): Aluminium neurotoxicity: neurobehavioural and oxidative aspects. Arch. Toxicol., 83(11): 965-978.

23. Zhang QL, Niu Q, Niu PY, Shi YT, Liu CY, DiGioacchino $M$, Zhang $L$, Zhang $C$ and Braga $M$ (2010): Bax gene silencing: a potential intervention in aluminum-induced neural cell death. J. Biol. Regul. Homeost. Agents, 24: 7-17.

24. So FV, Guthrie N, Chambers AF, Moussa M and Carroll KK (1996): Inhibition of human breast cancer cell proliferation and delay of mammary tumorigenesis by flavonoids and citrus juices. Nutr. Cancer, (26): 167181.

25. Bhalla $P$, Singla $N$ and Dhawan DK (2010): Potential of lithium to reduce aluminum-induced cytotoxic effects in rat brain. Biol. Metals, 23: 197-206.

26. Ondreicka R, Ginter $\mathbf{E}$ and Kortus J (2014): Chronic toxicity of aluminium in rats and mice and its effects on phosphorus metabolism. Brit. J. industr. Med., 23: 305314.

27. Al-Amoudi WM (2017): Effect of grapefruit juice on aluminum-induced hepatotoxicity in albino rats: histological, ultrastructural and histochemical assessment. Adv. Biosci. Biotechnol., 8: 463-477. 